\title{
Performance analysis of Weibull methods for estimation of wind speed distributions in the adamaoua region of Cameroon
}

\author{
Dieudonné Kidmo Kaoga ${ }^{1 *}$, Serge Doka Yamigno ${ }^{2}$, Danwe Raidandi ${ }^{3}$, Noël Djongyang ${ }^{1}$ \\ ${ }^{1}$ Department of Renewable Energy, Higher Institute of the Sahel, University of Maroua, PO Box 46 Maroua, Cameroon \\ ${ }^{2}$ Department of Physics, Higher Teacher's Training College, University of Maroua, PO Box 46 Maroua, Cameroon \\ ${ }^{3}$ Department of Mechanical Engineering, National Advanced Polytechnic School, University of Yaoundé I, \\ PO Box 8390 Yaoundé, Cameroon \\ *Corresponding author E-mail: kidmokaoga@gmail.com
}

Copyright $\odot 2014$ Dieudonné Kidmo Kaoga et al. This is an open access article distributed under the Creative Commons Attribution License, which permits unrestricted use, distribution, and reproduction in any medium, provided the original work is properly cited.

\begin{abstract}
This paper explores the performance analysis of five Weibull distribution methods to select the more accurate estimation for the Weibull parameters using time-series of measured daily wind speed data collected in three localities in the Adamaoua region of Cameroon. The Weibull distribution with two parameters, the shape $\mathrm{k}$, and the scale $\mathrm{C}$, was specifically considered to be a good quality probabilistic model for wind speed distributions. The five Weibull distribution methods proved to be effective in evaluating the parameters of the Weibull distribution. This fact was supported by the values of the root mean square error, the Chi-square $\left(\chi^{2}\right)$ and the correlation coefficient $\mathrm{R}^{2}$ which showed magnitudes very close to each other. In addition, the comparison between wind speed distributions predicted by the Weibull methods and wind speed distributions measured locally, suggested that the most accurate two-parameter Weibull distribution method is the Energy Pattern Factor Method (EPF). As a result, to reduce uncertainties related to the wind energy output calculation, the EPF is recommended for estimating wind speed distributions.
\end{abstract}

Keywords: Maximum Likelihood Method Modified Maximum Likelihood Method, Graphical Method, Energy Pattern Factor Method, and Empirical Method.

\section{Introduction}

Nowadays, all countries around the globe aim at reducing adverse effects of environmental pollution, fossil fuel consumption and natural depletion of resources at local, national and regional levels. Therefore, it's observed that the generation and consumption of energy harmless to the environment, has gained more and more momentum. Most promising renewable sources of energy with near-zero emissions have raised the need to enhance local energy supply. Among the renewable energy technologies, the generation of mechanical and electrical power by wind machines has emerged as a techno-economical viable and cost-effective option [1]. With the focus on local sustainable energy solutions, wind energy could be attractive for off-grid areas in the Adamaoua region of Cameroon where the remoteness of some cities is economically unattractive for the vertically integrated power utility, AES-SONEL operating the northern interconnected Grid. At the present time, wind energy as a renewable energy source has emerged as one of the friendliest sources of energy as it does not require any fuel to burn and hence does not produce any kind of pollutant [2]. As a random phenomenon, wind speed is the most significant parameter of the wind energy. As a result, an accurate determination of the probability distribution of wind speed is essential for predicting the energy output of a Wind Energy Conversion Systems (WECS). In the last few years, researchers in the wind engineering field and wind energy industry have devoted to the development of suitable predictive models to describe wind speed frequency distribution. The two-parameter Weibull Probability Density Function (PDF) has been used to represent wind speed distributions for applications in wind loads studies [3]. In addition, the Weibull PDF has been found as a useful and appropriate method of computing power output from wind-powered generators and applied to estimate potential power output at various sites across the continental United States [4]. In literature, many studies base their statistical analysis of wind characteristics and wind energy potential on the assumption that the Weibull distribution approximates wind speed [1, 
3-5]. There seems to be a compromise in the literature that the Weibull PDF with two parameters, the dimensionless shape parameterk, and the scale parameter $C$, is a good quality probabilistic model for wind speed at any location. It is obvious that the more appropriate Weibull estimation method shall provide accurate and efficient evaluation of wind energy potential. In this regard, a number of studies have been carried out by various researchers in order to assess wind energy potential by using the Weibull PDF [6-10] .Various methods have been effectively experimented for estimating the shape and scale parameters and the precision of each method varied according to the sample data distribution, which is basically location specific.

In the present study, five numerical methods, namely the maximum likelihood method, the modified maximum likelihood method, the energy pattern factor method, the graphical method, and the empirical method are explored and their accuracy compared for Banyo, Meiganga and Ngaoundéré in the Adamaoua region in Cameroon. The data collected for this study are daily synoptic observations from Banyo (1985 - 1995), Meiganga (1985 - 1995$)$ and Ngaoundéré (1985 - 2013). The aim of this work was to select a method that gives more accurate estimation for the Weibull parameters in order to reduce uncertainties related to the wind energy output calculation from any Wind Energy Conversion Systems (WECS).

\section{Materials and methods}

\subsection{Data source}

Time-series of measured daily wind speed data for the period between 1985 and 1995 for Banyo and Meiganga and for the period between 1985 and 2013 for Ngaoundéré, the only functional meteorological station to date. Fig. 1 shows monthly mean wind speed and wind speed standard deviation while the table 1 shows the geographic coordinates of the stations.

Table 1: Geographical Coordinates of the Three Selected Locations

\begin{tabular}{lll}
\hline Location & Variable & Value \\
\hline \multirow{2}{*}{ BANYO } & Latitude & $6^{\circ} 45^{\prime} 07^{\prime \prime} \mathrm{N}$ \\
& Longitude & $11^{\circ} 48^{\prime} 39^{\prime \prime} \mathrm{E}$ \\
& Anemometer Height & $10 \mathrm{~m}$ \\
MEIGANGA & Elevation & 1081 meters above sea level \\
& Latitude & $6^{\circ} 31^{\prime} 17^{\prime \prime} \mathrm{N}$ \\
& Longitude & $14^{\circ} 17^{\prime} 51^{\prime \prime} \mathrm{E}$ \\
NGAOUNDERE & Anemometer Height & $10 \mathrm{~m}$ \\
& Elevation & 1037 meters above sea level \\
& Latitude & $7^{\circ} 21^{\prime} 25^{\prime} \mathrm{N}$ \\
& Longitude & $13^{\circ} 33^{\prime} 42^{\prime \prime} \mathrm{E}$ \\
& Anemometer Height & $10 \mathrm{~m}$ \\
\hline
\end{tabular}

Table 2: Mean Wind Speed and Wind Speed Standard Deviation

\begin{tabular}{|c|c|c|c|c|c|c|}
\hline \multirow[b]{2}{*}{ Period } & \multicolumn{2}{|c|}{ BANYO } & \multicolumn{2}{|c|}{ MEIGANGA } & \multicolumn{2}{|c|}{ NDERE } \\
\hline & $\bar{V}(\mathrm{~m} / \mathrm{s})$ & $\sigma(\mathrm{m} / \mathrm{s})$ & $\bar{V}(\mathrm{~m} / \mathrm{s})$ & $\sigma(\mathrm{m} / \mathrm{s})$ & $\bar{V}(\mathrm{~m} / \mathrm{s})$ & $\sigma(\mathrm{m} / \mathrm{s})$ \\
\hline Jan. & 1.946 & 0.477 & 1.778 & 0.659 & 2.266 & 0.565 \\
\hline Feb. & 1.942 & 0.315 & 1.765 & 0.551 & 2.364 & 0.616 \\
\hline Mar. & 1.963 & 0.324 & 1.748 & 0.407 & 2.376 & 0.592 \\
\hline April & 1.845 & 0.336 & 1.793 & 0.513 & 2.171 & 0.511 \\
\hline May & 1.862 & 0.326 & 1.630 & 0.345 & 2.094 & 0.521 \\
\hline June & 1.780 & 0.366 & 1.621 & 0.510 & 2.100 & 0.544 \\
\hline July & 1.773 & 0.292 & 1.634 & 0.487 & 2.075 & 0.595 \\
\hline Aug. & 1.738 & 0.369 & 1.628 & 0.349 & 2.017 & 0.410 \\
\hline Sept. & 1.590 & 0.540 & 1.618 & 0.472 & 1.997 & 0.571 \\
\hline Oct. & 1.749 & 0.483 & 1.688 & 0.387 & 2.060 & 0.413 \\
\hline Nov. & 1.750 & 0.693 & 1.726 & 0.373 & 2.111 & 0.446 \\
\hline Dec. & 1.773 & 0.605 & 1.747 & 0.413 & 2.221 & 0.471 \\
\hline Avg. & 1.809 & 0.427 & 1.698 & 0.455 & 2.154 & 0.521 \\
\hline
\end{tabular}

\subsection{Measured mean wind speed and standard deviation}

The monthly mean wind speed $\bar{V}$ and the standard deviation $\sigma$ of the time-series of measured daily wind speed data are determined using Eqs. 1 and 2 [10], [11]: 
$\bar{V}=\frac{1}{N}\left(\sum_{i=1}^{N} V_{i}\right)$

$\sigma=\left[\frac{1}{N-1} \sum_{i=1}^{n}\left(V_{i}-\bar{V}\right)^{2}\right]^{1 / 2}$

Where: $\bar{V}=$ mean wind speed $[\mathrm{m} / \mathrm{s}]$

$\sigma=$ standard deviation of the observed data $[\mathrm{m} / \mathrm{s}]$

$N=$ number of measured daily wind speed data.

\subsection{Measured wind speed probability distributions}

In a study, Lysen [12] quoted that to determine frequency distributions of the wind speed; we must first divide the wind speed domain into a number of intervals, mostly of equal width of $1 \mathrm{~m} / \mathrm{s}$ or $0.5 \mathrm{~m} / \mathrm{s}$. As a result, for a suitable statistical analysis, the wind speed data in time series format were transformed into frequency distribution format. In this process, the wind speeds were grouped into class interval and the mean wind speed defined for each class as illustrated in the Table 3. Based on the wind speed classes, the frequency distribution of the measured wind speed was established and plotted as shown by the Fig. 1 while the cumulative frequency distribution of the measured wind speed displayed in the Fig. 2.

Table 3: Wind Speed Classes

\begin{tabular}{ccc}
\hline Class & Range $(\mathrm{m} / \mathrm{s})$ & Mean Wind Speed $\bar{V}(\mathrm{~m} / \mathrm{s})$ \\
\hline 1 & $0<V<1$ & 0.5 \\
2 & $1 \leq V<2$ & 1 \\
3 & $2 \leq V<3$ & 2 \\
4 & $3 \leq V<4$ & 3 \\
5 & $4 \leq V<5$ & 4 \\
6 & $5 \leq V<6$ & 5 \\
7 & $V \geq 6$ & 6 \\
\hline
\end{tabular}

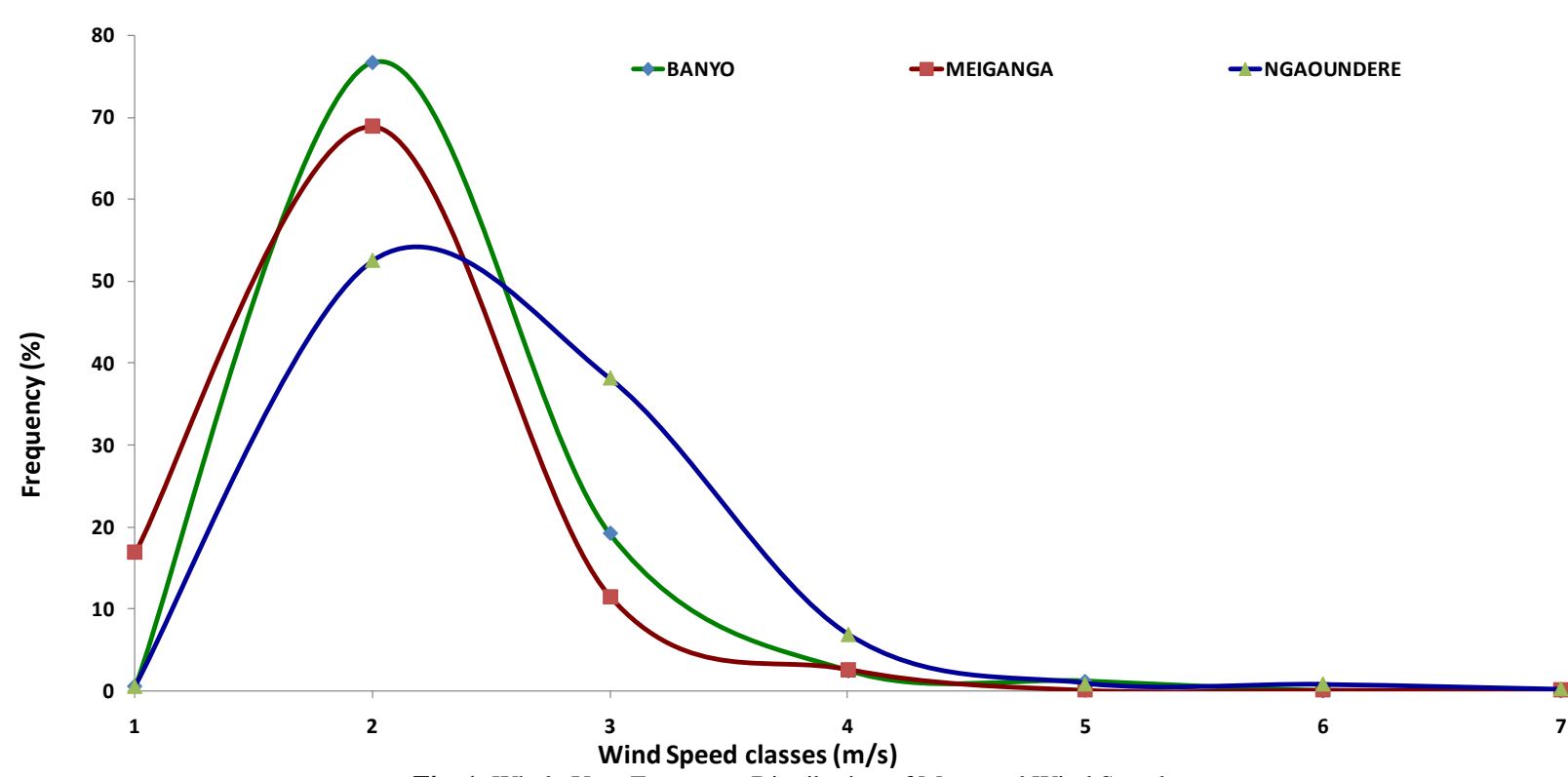

Fig. 1: Whole Year Frequency Distribution of Measured Wind Speed 


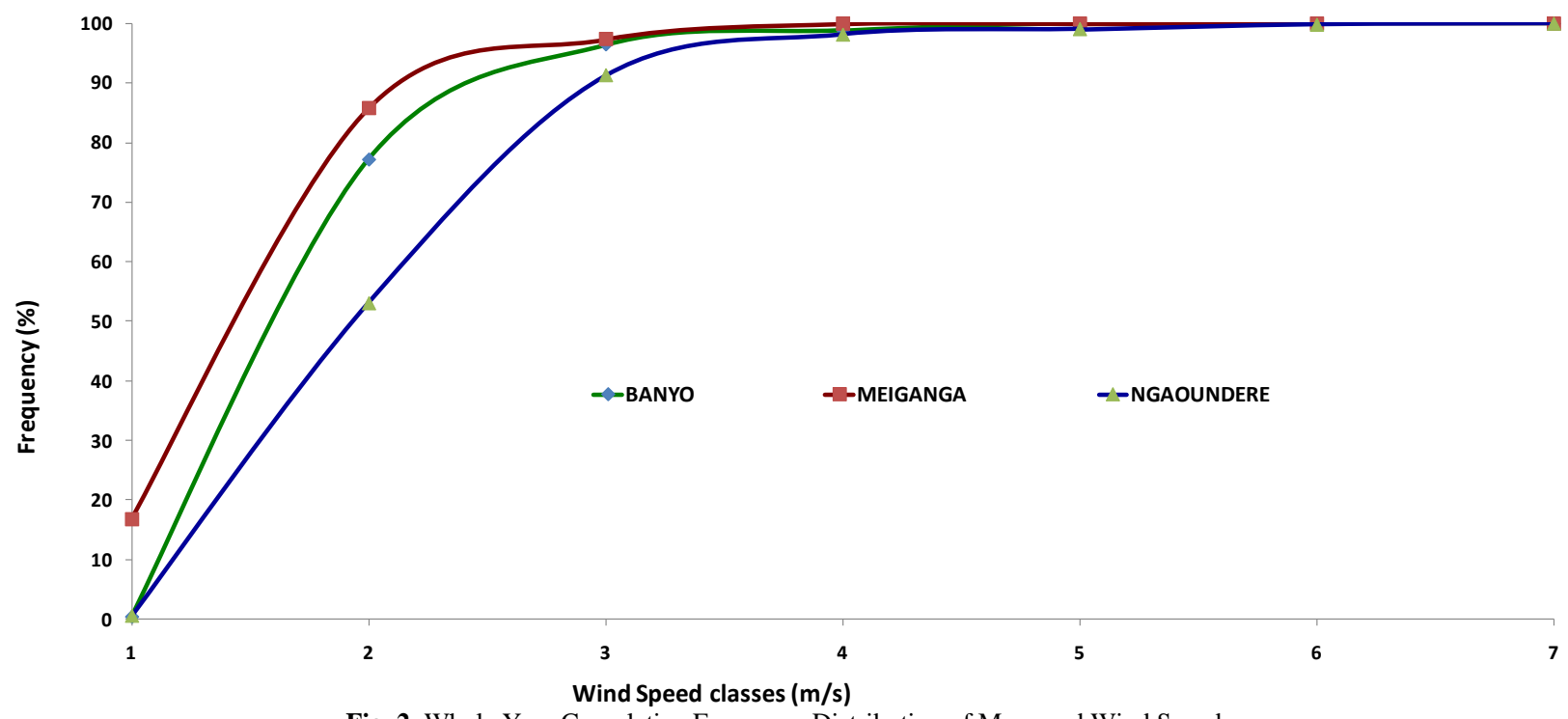

Fig. 2: Whole Year Cumulative Frequency Distribution of Measured Wind Speed

\subsection{Methods to estimate Weibull parameters}

The variation in wind speed are most often described by the Weibull PDF with two parameters, the dimensionless Weibull shape parameter $k$, and the Weibull scale parameter $C$ which have reference values in the units of wind speed. The PDF function $f(V)$ is given by Eq. 3 [3-11]:

$f(V)=(k / C) \cdot(V / C)^{k-1} \cdot \exp \left(-(V / C)^{k}\right)$

Where: $f(V)=$ probability of observing wind speed $V$

$V=$ wind speed $[\mathrm{m} / \mathrm{s}]$

$C=$ Weibull scale parameter $[\mathrm{m} / \mathrm{s}]$

$k=$ Weibull shape parameter

The corresponding cumulative distribution function is given by Eq. 4:

$F(V)=1-\exp \left(-(V / C)^{k}\right)$

To estimate the dimensionless shape $k$, and the scale $C$, parameters of the Weibull distribution function, five methods have been computed.

\subsubsection{Graphical method}

The graphical method (GM) is achieved through the cumulative distribution function. In this distribution method, the wind speed data are interpolated by a straight line, using the concept of least squares regression [3], [6], [9]. The logarithmic transformation is the foundation of this method. By converting Eq. 4 into logarithmic form, Eq. 5 is obtained:

$\ln [-\ln (1-F(V))]=k \ln (V)-k \ln (C)$

The Weibull shape and scale parameters are estimated by plotting $\ln (V)$ against $\ln [-\ln (1-F(V))]$ in which a straight line is determined. In order to generate the line of best fit, observations of calms should be omitted from the data. The Weibull shape parameter $k$ is the slope of the line and the y-intercept is the value of the term $-k \ln (C)$.

\subsubsection{Maximum likelihood method}

The Maximum Likelihood Estimation method (MLM) is a mathematical expression known as a likelihood function of the wind speed data in time series format. The MLM method was used by Costa Rocha et al [6] quoting Stevens and Smulders [13] in their study for the estimation of parameters of the Weibull wind speed distribution for wind energy utilization purposes. The MLM method is solved through numerical iterations to determine the parameters of the Weibull distribution. The shape factor $k$ and the scale factor $C$ are estimated by Eqs. 6 and 7 [6], 7], [13], [14]:

$k=\left[\left(\sum_{i=1}^{n} V_{i}^{k} \ln \left(V_{i}\right)\right) /\left(\sum_{i=1}^{n} V_{i}^{k}\right)-\left(\sum_{i=1}^{n} \ln \left(V_{i}\right)\right) / n\right]^{-1}$

$c=\left(\frac{1}{n} \sum_{i=1}^{n} V_{i}^{k}\right)^{1 / k}$

Where: $n=$ number of none zero data values;

$i=$ measurement interval;

$V_{i}=$ wind speed measured at the interval $i[\mathrm{~m} / \mathrm{s}]$. 


\subsubsection{Modified maximum likelihood method}

The Modified Maximum Likelihood Estimation method (MMLM) is used only for wind speed data available in the Weibull distribution format. The MMLM method is solved through numerical iterations to determine the parameters of the Weibull distribution [6], [13]. The shape factor $k$ and the scale factor $C$ are estimated by Eqs. 8 and 9.

$k=\left[\left(\sum_{i=1}^{n} V_{i}^{k} \ln \left(V_{i}\right) f\left(V_{i}\right)\right) /\left(\sum_{i=1}^{n} V_{i}^{k} f\left(V_{i}\right)\right)-\left(\sum_{i=1}^{n} \ln \left(V_{i}\right) f\left(V_{i}\right)\right) /(f(V \geq 0))\right]^{-1}$

$c=\left[\left(\sum_{i=1}^{n} V_{i}^{k} f\left(V_{i}\right)\right) /(f(V) \geq 0)\right]^{1 / k}$

Where: $f\left(V_{i}\right)=$ Weibull frequency with which the wind speed falls within the interval $i$; $f(V \geq 0)=$ Probability of wind speed $V \geq 0$.

\subsubsection{Empirical method}

The Weibull parameters $k$ and $C$ for the empirical method (EM) are determined using average wind speed and standard deviation as follows [6]:

$k=(\sigma / \bar{V})^{-1.089}$

$C=\bar{V} / \Gamma(1+1 / k)$

The standard deviation $\sigma$ of the observed data is determined using Eqs. 12 and 13.

$\sigma=C\left[\Gamma(1+2 / k)-\Gamma^{2}(1+1 / k)\right]^{1 / 2}$

Where the standard gamma function is given by Eq. 13:

$\Gamma(x)=\int_{0}^{\infty} t^{x-1} \exp (-t) d t$

The gamma function used by J.F. Manwell et al [15] quoting Jamil [16] is given by Eq. 14:

$\Gamma(x)=(\sqrt{2 \pi x})\left(x^{x-1}\right)\left(e^{-x}\right)\left(1+1 / 12 x+1 / 288 x^{2}-139 / 51840 x^{3}+\cdots\right)$

\subsubsection{Energy pattern factor method}

The energy pattern factor method (EPF) is related to the averaged data of wind speed and is defined by Eqs. 15,16 and 17 [6], [17] as follow:

$E_{p f}=\overline{V^{3}} / \bar{V}^{3}=\left(\frac{1}{n} \sum_{i=1}^{n}{\overline{V_{i}}}^{3}\right) /\left(\frac{1}{n} \sum_{i=1}^{n} \bar{V}_{i}\right)^{3}$

$k=1+3.69 /\left(E_{p f}\right)^{2}$

Where: $E_{p f}$ is the energy pattern factor

The Weibull scale parameter $C$ is determined using the following equation:

$C=\left(\frac{1}{n} \sum_{i=1}^{n} \bar{V}_{i}^{k}\right)^{1 / k}$

\subsection{Performance evaluation of the Weibull distribution methods}

In order to evaluate the performance of the five Weibull distributions methods, the correlation coefficient $R^{2}$, the root mean square error (RMSE) and the chi-square analysis have been carried out.

The RMSE parameter gives the deviation between the predicted and the experimental values, it should be as close to zero as possible, and it is expressed as [6], [9]:

$R M S E=\left[\frac{1}{N} \sum_{i=1}^{N}\left(y_{i}-x_{i}\right)^{2}\right]^{1 / 2}$

Chi-square test returns the mean square of the deviations between the experimental and the calculated values for the distributions and it is expressed as [6], [9]:

$\chi^{2}=\frac{\sum_{i=1}^{n}\left(y_{i}-x_{i}\right)^{2}}{N-n}$

The correlation coefficient $R^{2}$ shows the ability of the model, and the highest value it can get is $1 . R^{2}$ is determined by Eq. 20 [6], [9]:

$R^{2}=\frac{\sum_{i=1}^{N}\left(y_{i}-z_{i}\right)^{2}-\sum_{i=1}^{N}\left(y_{i}-x_{i}\right)^{2}}{\sum_{i=1}^{N}\left(y_{i}-z_{i}\right)^{2}}$

Where: $y_{i}$ is the actual data, $x_{i}$ is the predicted data using the Weibull distribution, $z$ is the mean value of $y_{i}, N$ is the number of all observed wind data and $\mathrm{n}$ is the number of constants used ;

\section{Results}

For each of the five methods considered in the analysis, and for the whole year, Figs. 3 to 5 show the Weibull PDF $f(V)$, versus the mean wind speed $\bar{V}$, for measured daily wind speed data for the period between 1985 and 1995 for Banyo and Meiganga, and for the period between 1985 and 2013 for Ngaoundéré. It can be observed from these figures how the curves representing the Weibull PDF, for each of the proposed methods considered in the analysis, match the histograms of measured daily wind speed data, illustrating the method that fits best to the measured wind speed data. 
Then, tables 4 to 6 illustrate for the whole year, Weibull PDF parameters and statistical analysis for the three selected localities. Table 7 shows, for the whole year, the comparison between the mean wind speed standard deviation predicted by the Weibull methods and the measured wind speed data while table 8 gives an idea about the comparison between the mean wind speeds predicted by the Weibull methods and the measured wind speed data.

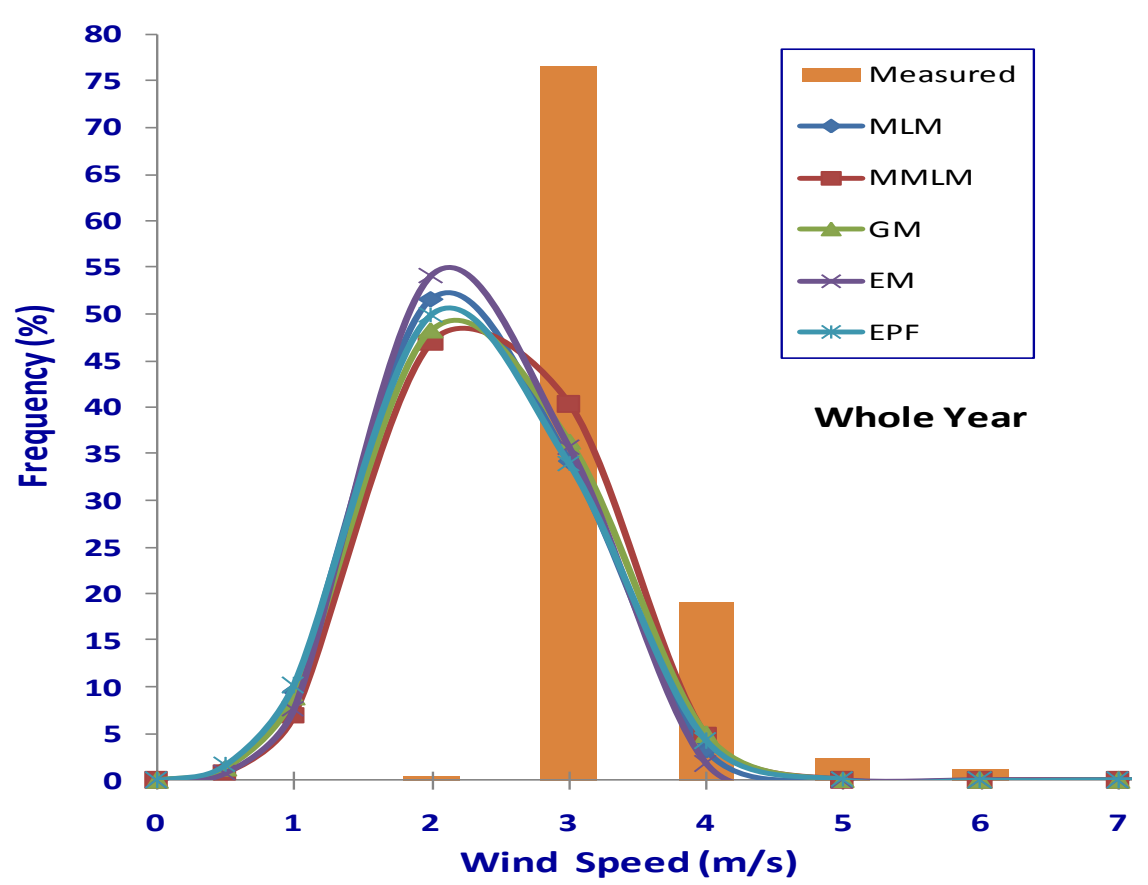

Fig. 3: Whole Year Weibull Distribution of Banyo

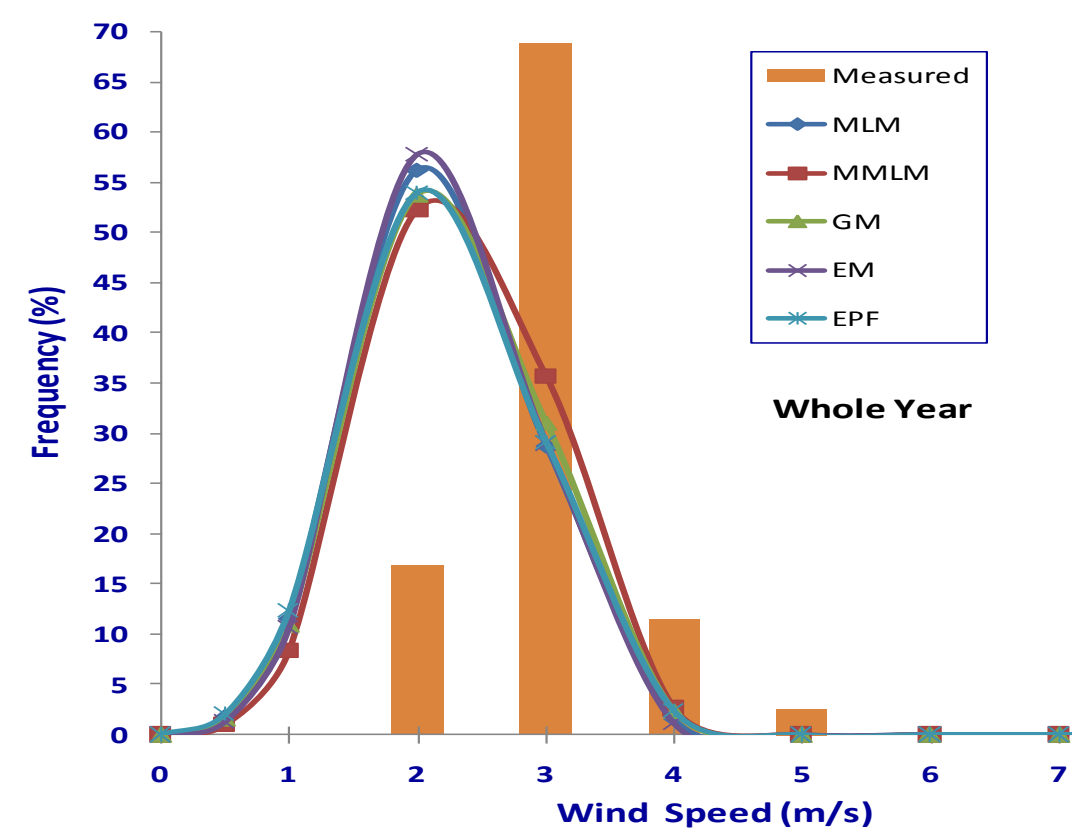

Fig. 4: Whole Year Weibull Distribution of Meiganga 


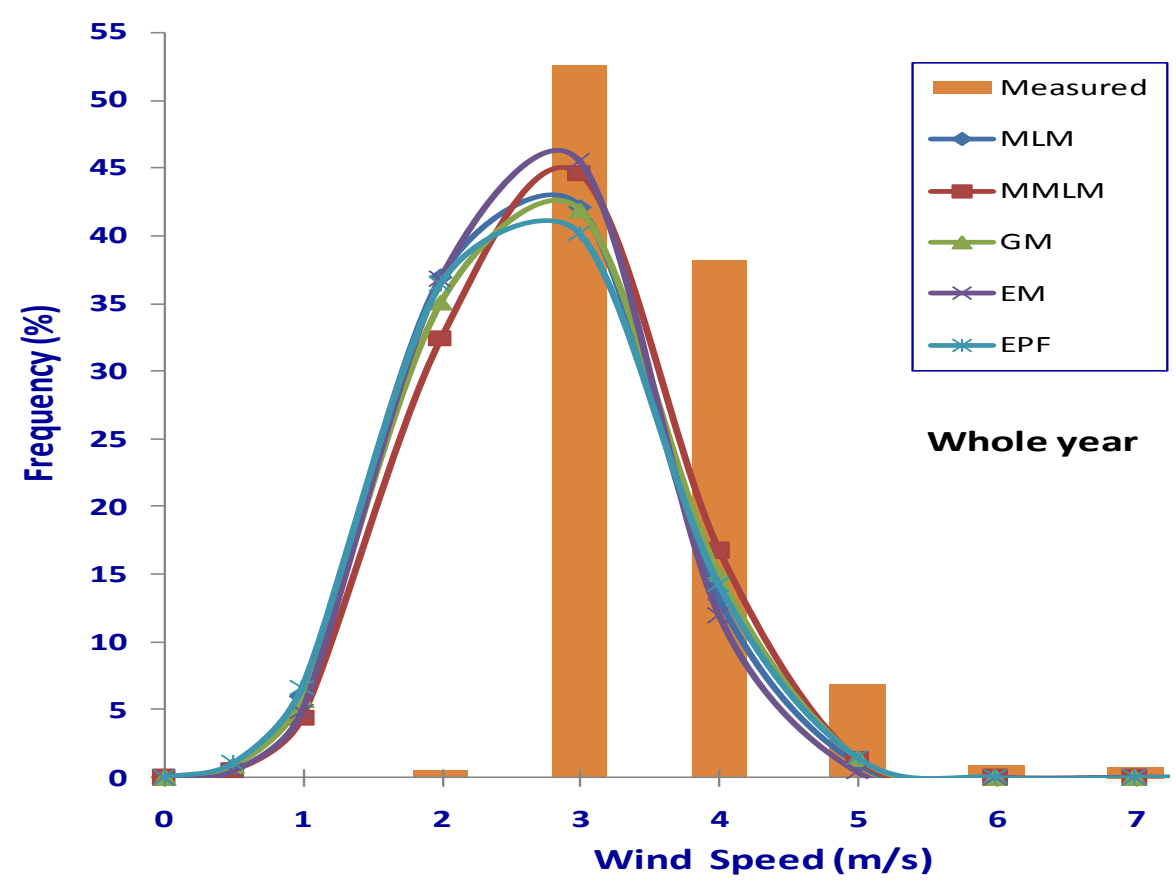

Fig. 5: Whole Year Weibull Distribution of Ngaoundéré

\section{Discussions}

a) Performance of the Weibull distribution methods

The proposed five methods are effective in evaluating the parameters of the Weibull distribution for the available data. This fact is supported by the values of RMSE, Chi-square and $\mathrm{R}^{2}$, which have magnitudes very close to each other for the five Weibull PDF methods based on the data collected in the localities of Banyo, Meiganga and Ngaoundéré. Obviously, the best parameters estimation shall disclose the lowest value of RMSE and chi-square, and the highest value of $\mathrm{R}^{2}$. As a result, it can be concluded that for each of the three selected localities, the energy pattern factor method is the most accurate Weibull PDF method followed by the graphical method and the maximum likelihood method. The least precise methods are the empirical method followed by the modified maximum likelihood method.

b) Weibull parameters $\mathrm{C}$ and $\mathrm{k}$

The Weibull shape $k$ parameter indicates the breadth of a distribution of wind speeds. Lower $k$ values mean that winds tend to vary over a large range of speeds while higher $\mathrm{k}$ values correspond to wind speeds staying within a narrow range. It's observed that whole year Weibull $k$ values vary from 2.928621 using the EPF to 3.398592 using the EM for Banyo while Meiganga presents values of the parameter $k$ ranging from 2.882764 using the EPF to 3.353425 using the EM. As for Ngaoundéré, whole year Weibull $k$ values vary from 2.848433 using the EPF to 3.298026 using the EM. It can be noted that Weibull $k$ values are within the range for most wind conditions. Typical Weibull $k$ values for most wind conditions ranges from 1.500 to 3.000 [18]. As a result it can be concluded from the observed $k$ values that the higher the $k$ value the less accurate the Weibull PDF method. On the other hand, the Weibull scale $C$ parameter shows how "windy" a location is or, in other words, how high the annual mean speed is. It's observed that whole year Weibull $C$ values vary from 2.011501 using the MLM to 2.146577 using the MMLM for Banyo while Meiganga presents values of the parameter $C$ ranging from 1.890152 using the MLM to 2.025571 using the MMLM. As for Ngaoundéré, whole year Weibull $C$ values vary from 2.400770 using the EM to 2.537142 using the MMLM. These two Weibull parameters determine the wind speed for optimum performance of a WECS as well as the speed range over which it's expected to operate at 10 meters height above ground level.

The predicted Weibull PDF parameters $k$ and $C$ allowed calculating the whole year mean wind speed and its standard deviation for each method, and the results are presented in tables 6 and 7. When considering the standard deviation analysis, it can be observed that all the Weibull PDF methods show significant errors because of the quality of measured wind speed data. For each of the three localities the EM presents the lowest error, greater than $18.41 \%$ while the EPF presents the highest error, greater than $28.73 \%$. The comparison between the mean wind speed predicted by the Weibull methods and the measured wind speed data showed that the MMLM presents the highest error, greater than $5.28 \%$ followed by the GM. The EPF and EM showed the lowest errors, which are $0.00 \%$ followed by the MLM. 
Table 4: Whole year Weibull parameters and statistical analysis -Banyo

\begin{tabular}{cccccc}
\hline \multirow{2}{*}{ Weibull methods } & \multicolumn{2}{c}{ Weibull parameters } & \multicolumn{3}{c}{ Statistical tests } \\
& Shape k & Scale C & RMSE & $\chi^{2}$ (Chi-square) & $\mathrm{R}^{\mathbf{2}}$ \\
\hline MLM & 3.081757 & 2.011501 & 0.044074 & 0.002136 & 0.988276 \\
MMLM & 3.292515 & 2.146577 & 0.044842 & 0.002173 & 0.988071 \\
GM & 3.020000 & 2.085689 & 0.043448 & 0.002106 & 0.988442 \\
EM & 3.398592 & 2.010759 & 0.045915 & 0.002225 & 0.987786 \\
EPF & 2.928621 & 2.027143 & 0.042997 & 0.002084 & 0.988562 \\
\hline
\end{tabular}

Table 5: Whole Year Weibull Parameters and Statistical Analysis -Meiganga

\begin{tabular}{|c|c|c|c|c|c|}
\hline \multirow{2}{*}{ Weibull methods } & \multicolumn{2}{|c|}{ Weibull parameters } & \multicolumn{3}{|c|}{ Statistical tests } \\
\hline & Shape k & Scale C & RMSE & $\chi^{2}$ (Chi-square) & $\mathrm{R}^{2}$ \\
\hline MLM & 3.061143 & 1.890152 & 0.039015 & 0.001823 & 0.991908 \\
\hline MMLM & 3.283240 & 2.025571 & 0.039644 & 0.001852 & 0.991778 \\
\hline GM & 3.016000 & 1.942145 & 0.038504 & 0.001799 & 0.992014 \\
\hline EM & 3.353425 & 1.891196 & 0.040754 & 0.001904 & 0.991548 \\
\hline $\mathrm{EPF}$ & 2.882764 & 1.903721 & 0.037753 & 0.001764 & 0.992170 \\
\hline
\end{tabular}

Table 6: Whole Year Weibull Parameters and Statistical Analysis -Ngaoundéré

\begin{tabular}{|c|c|c|c|c|c|}
\hline \multirow{2}{*}{ Weibull methods } & \multicolumn{2}{|c|}{ Weibull parameters } & \multicolumn{3}{|c|}{ Statistical tests } \\
\hline & Shape k & Scale C & RMSE & $\chi^{2}$ (Chi-square) & $\mathrm{R}^{2}$ \\
\hline MLM & 3.015997 & 2.401900 & 0.029560 & 0.001381 & 0.995017 \\
\hline MMLM & 3.193626 & 2.537142 & 0.030442 & 0.001422 & 0.994868 \\
\hline GM & 2.978000 & 2.461917 & 0.029289 & 0.001368 & 0.995063 \\
\hline EM & 3.298026 & 2.400770 & 0.031181 & 0.001457 & 0.994744 \\
\hline $\mathrm{EPF}$ & 2.848433 & 2.416313 & 0.028513 & 0.001332 & 0.995194 \\
\hline
\end{tabular}

Table 7: Comparison between the Mean Wind Speed Standard Deviation Predicted By the Weibull Methods and the Measured Data

\begin{tabular}{|c|c|c|c|c|c|c|}
\hline \multirow{2}{*}{ Methods } & \multicolumn{2}{|c|}{ Banyo } & \multicolumn{2}{|c|}{ Meiganga } & \multicolumn{2}{|c|}{ Ngaoundéré } \\
\hline & $\sigma(\mathrm{m} / \mathrm{s})$ & Error $(\%)$ & $\sigma(\mathrm{m} / \mathrm{s})$ & Error $(\%)$ & $\sigma(\mathrm{m} / \mathrm{s})$ & Error $(\%)$ \\
\hline MLM & 0.637912 & $33.04 \%$ & 0.602862 & $24.45 \%$ & 0.775840 & $32.83 \%$ \\
\hline MMLM & 0.643548 & $33.62 \%$ & 0.608725 & $25.18 \%$ & 0.780585 & $33.24 \%$ \\
\hline GM & 0.672940 & $36.52 \%$ & 0.627334 & $27.40 \%$ & 0.803869 & $35.17 \%$ \\
\hline EM & 0.574512 & $25.65 \%$ & 0.558239 & $18.41 \%$ & 0.718735 & $27.49 \%$ \\
\hline $\mathrm{EPF}$ & 0.671420 & $36.38 \%$ & 0.639104 & $28.73 \%$ & 0.819548 & $36.41 \%$ \\
\hline Measured & 0.427167 & - & 0,455463 & - & 0.521142 & - \\
\hline
\end{tabular}

Table 8: Comparison between the Mean Wind Speeds Predicted By the Weibull Methods and the Measured Data

\begin{tabular}{|c|c|c|c|c|c|c|}
\hline \multirow{2}{*}{ Methods } & \multicolumn{2}{|c|}{ Banyo } & \multicolumn{2}{|c|}{ Meiganga } & \multicolumn{2}{|c|}{ Ngaoundéré } \\
\hline & $\bar{V}(\mathrm{~m} / \mathrm{s})$ & Error $(\%)$ & $\bar{V}(\mathrm{~m} / \mathrm{s})$ & Error $(\%)$ & $\bar{V}(\mathrm{~m} / \mathrm{s})$ & Error $(\%)$ \\
\hline MLM & 1.799214 & $-0.55 \%$ & 1.689949 & $-0.48 \%$ & 2.146429 & $-0.36 \%$ \\
\hline MMLM & 1.926679 & $6.12 \%$ & 1.817809 & $6.60 \%$ & 2.273814 & $5.28 \%$ \\
\hline GM & 1.855124 & $2.50 \%$ & 1.745326 & $2.69 \%$ & 2.208138 & $2.45 \%$ \\
\hline EM & 1.809279 & $0.00 \%$ & 1.697965 & $0.00 \%$ & 2.154233 & $0.00 \%$ \\
\hline EPF & 1.809279 & $0.00 \%$ & 1.697965 & $0.00 \%$ & 2.154233 & $0.00 \%$ \\
\hline Measured & 1.809279 & - & 1.697965 & - & 2.154233 & - \\
\hline
\end{tabular}

\section{Conclusions}

The performance analysis of five Weibull methods for estimation of wind speed distributions in three selected locations in the Adamaoua region of Cameroon has been the subject of this paper. The aim was to select the most accurate twoparameter Weibull PDF method for assessing wind speed distributions for each of the three selected locations in the Adamaoua region of Cameroon as opposed to simply using the measured data in time-series or the frequency distribution of the measured data collected. The following main conclusions can be drawn from the present study:

1) The studied Weibull methods are effective in evaluating the parameters of the Weibull distribution for the available data since the values of the RMSE, Chi-square and $\mathrm{R}^{2}$ have magnitudes very close to each other ;

2) The comparison between the mean wind speed predicted by the Weibull methods and the measured mean wind speed data, showed that the MMLM and the GM are the least effective methods to fit Weibull distribution curves for wind speed data;

3) The comparison between the standard deviation predicted by the Weibull methods and the standard deviation of measured data revealed that EPF method has the highest errors followed by the GM and MLM methods while the 
EM showed the smallest error. The quality of wind speed data and the frequency distribution format are thought to be accountable ;

4) The results therefore, strongly recommend using as necessary the EPF method, as the more accurate estimation of the Weibull parameters in order to reduce uncertainties related to the wind energy output calculation.

5) The MLM method could be used as an alternative to the EPF method.

\section{References}

[1] Abdeen Mustafa Omer, "On the wind energy resources of Sudan", Renewable and Sustainable Energy Reviews, 12(8), (2006), 2117-2139, http://dx.doi.org/10.1016/j.rser.2006.10.010.

[2] Shafiqur Rehman, "Prospects of wind farm development in Saudi Arabia", Renewable Energy, 30(3), (2005), 447-463, http://dx.doi.org/10.1016/j.renene.2004.04.008.

[3] [3] C.G. Justus, W.R. Hargraves, A. Mikhail and D. Grabber, "Methods for estimating wind speed frequency distributions", Journal of applied meteorology, 17(3), (1978), 350-353, http://dx.doi.org/10.1175/1520-0450 (1978)017<0350:MFEWSF>2.0.CO;2.

[4] C.G. Justus, W.R. Hargraves and Ali Yalcin, "Nationwide assessment of potential output from wind-powered generators", Journal of applied meteorology, 15(7), (1976), 673-678, http://dx.doi.org/10.1175/1520-0450 (1976)015<0673: NAOPOF>2.0.CO; 2.

[5] B. Safari, J. Gasore, "A statistical investigation of wind characteristics and wind energy potential based on the Weibull and Rayleigh models in Rwanda", Renewable Energy, 35(12), (2010), 2874-2880, http://dx.doi.org/10.1016/j.renene.2010.04.032.

[6] P. A. Costa Rocha, R. Coelho de Sousa, C. Freitas de Andrade, M. Vieira da Silva, "Comparison of seven numerical methods for determining Weibull parameters for wind energy generation in the northeast region of Brazil", Applied Energy, 89(1), (2012), 395-400, http://dx.doi.org/10.1016/j.apenergy.2011.08.003

[7] K.D. Kidmo, N. Djongyang, Y.S. Doka, R. Danwe, "Assessment of wind energy potential for small scale water pumping systems in the north region of Cameroon", International Journal of Basic and Applied Sciences, 3(1), (2014), 38-46, Doi: 10.14419/ijbas.v3i1.1769 http://dx.doi.org/10.14419/ijbas.v3i1.1769.

[8] A.W. Dahmounia, M. Ben Salahc, F. Askrib, C. Kerkenia, S. Ben Nasrallahb, "Assessment of wind energy potential and optimal electricity generation in Borj-Cedria, Tunisia", Renewable and Sustainable Energy Reviews, 15(1), (2011), 815-820, http://dx.doi.org/10.1016/j.rser.2010.07.020.

[9] I. Fyrippis, P. J. Axaopoulos, G. Panayiotou, "Wind energy potential assessment in Naxos Island, Greece", Applied Energy, 87(2), (2010), 577-586, http://dx.doi.org/10.1016/j.apenergy.2009.05.031.

[10] A. N. Celik, "A statistical analysis of wind power density based on the Weibull and Rayleigh models at the southern region of Turkey" Renewable Energy, 29(4), (2004), 593-604, http://dx.doi.org/10.1016/j.renene.2003.07.002

[11] Y. Oner, S. Ozcira, N. Bekiroglu, I. Senol, "A comparative analysis of wind power density prediction methods for Çanakkale, Intepe region, Turkey", Renewable and Sustainable Energy Reviews, 23 (2013), 491-502, http://dx.doi.org/10.1016/j.rser.2013.01.052

[12] E.H. lysen, Introduction to wind energy, Consultancy Services Wind Energy Developing Countries. CWO 82 May 1, 1983 (2nd edition).

[13] M.J. Stevens and P.T. Smulders, "The estimation of parameters of the Weibull wind speed distribution for wind energy utilization purposes", Wind Eng., 3 (2), (1979), 132-145.

[14] T.-J. Chang et al., "Assessment of wind characteristics and wind turbine characteristics in Taiwan", Renewable Energy,28 (6), (2003), 851871, http://dx.doi.org/10.1016/S0960-1481(02)00184-2

[15] M. Jamil, S. Parsa, M. Majidi, "Wind Power Statistics and Evaluation of Wind Energy Density", Renewable Energy, 6(5-6), (1995), 623-628, http://dx.doi.org/10.1016/0960-1481(95)00041-H

[16] J.F. Manwell, J.G. McGowan and A.L. Rogers, Wind energy explained: Theory, design and application, John Wiley and Sons Ltd., (2002). http://dx.doi.org/10.1002/0470846127.

[17] Y.M. Kantar, M. Kurban and F.O. Hocaoglu, "Comparison of six different parameter estimation methods in wind power applications", Scientific Research and Essays, 6(32), (2011), 6594-6604, DOI: 10.5897/SRE11.549 http://dx.doi.org/10.5897/SRE11.549.

[18] J. Waewsak, C. Chancham, M. Landry, Y. Gagnon, "An Analysis of Wind Speed Distribution at Thasala, Nakhon Si Thammarat, Thailand", $\begin{array}{lllll}\text { Journal of Sustainable Energy \& Environment 2(2), 2011, 51-55, available online: } & \end{array}$ http://www.jseejournal.com/JSEE\%202011/JSEE\%20Vol\%202\%20Issue\%202/7.\%20An\%20analysis\%20of\%20wind\%20pp.51-55.pdf, last visit :28/07/2014. 